\title{
LED spectral imaging with food and agricultural applications
}

\section{Carstensen, Jens Michael}

\section{Published in:}

Proceedings of SPIE

Link to article, DOI:

$10.1117 / 12.2304698$

Publication date:

2018

Document Version

Publisher's PDF, also known as Version of record

Link back to DTU Orbit

Citation (APA):

Carstensen, J. M. (2018). LED spectral imaging with food and agricultural applications. In Proceedings of SPIE (Vol. 10656). [1065604 ] SPIE - International Society for Optical Engineering. Proceedings of SPIE - The International Society for Optical Engineering https://doi.org/10.1117/12.2304698

\section{General rights}

Copyright and moral rights for the publications made accessible in the public portal are retained by the authors and/or other copyright owners and it is a condition of accessing publications that users recognise and abide by the legal requirements associated with these rights.

- Users may download and print one copy of any publication from the public portal for the purpose of private study or research.

- You may not further distribute the material or use it for any profit-making activity or commercial gain

- You may freely distribute the URL identifying the publication in the public portal

If you believe that this document breaches copyright please contact us providing details, and we will remove access to the work immediately and investigate your claim 


\title{
LED spectral imaging with food and agricultural applications
}

\author{
Jens Michael Carstensen
}

Jens Michael Carstensen, "LED spectral imaging with food and agricultural applications," Proc. SPIE 10656, Image Sensing Technologies: Materials, Devices, Systems, and Applications V, 1065604 (14 May 2018); doi: 10.1117/12.2304698

Event: SPIE Commercial + Scientific Sensing and Imaging, 2018, Orlando, Florida, United States 


\title{
LED spectral imaging with food and agricultural applications
}

\author{
Jens Michael Carstensen*, DTU Compute, DK-2800 Kgs. Lyngby, Denmark and Videometer A/S, \\ Lyngso Allé 3, DK-2970 Horsholm, Denmark
}

\begin{abstract}
Strobed LED spectral imaging systems share some principles with illumination filter wheel systems. The major advantages of strobed LED systems are: 1) speed, 2) no mechanical movement, 3) no dependency on unstable broadspectrum incandescent light source, 4) potential for high dynamic range imaging through the illumination, and 5) combined spectral reflectance imaging and spectral fluorescence imaging. All of the above advantages are exploited in the proposed system where the spectral illumination source is combined with an integrating sphere and a calibration model that provides traceability, high reproducibility, spatial homogeneity, and focus on chemical properties of a heterogenous sample. Application areas of such systems are quite broad and high performance systems are seen within fields like agriculture, food, pharmaceuticals, medical devices, cosmetics, forensics, cultural heritage, and general manufacturing. We will present the elements of our strobed LED imaging systems and highlight how such systems can be advantageous to other spectral imaging techniques like pushbroom imaging. The powerful multivariate analysis technique, normalized canonical discriminant analysis (nCDA) is used to optimize the application performance as well as to get information about the data/noise structure and importance of specific spectral ranges. The performance is illustrated on a number of real applications from industries within the above mentioned fields. Applications on agricultural seed analysis, coating analysis, food contamination, and counterfeit detection will be shown.
\end{abstract}

Keywords: hyperspectral, multispectral, agricultural imaging, adulteration, seed imaging, food contaminants, food imaging, coating analysis

\section{INTRODUCTION}

Spectral imaging systems are gaining importance these years due to more and more powerful technologies being developed mainly addressing applications where traditional color imaging or traditional spectroscopy do not meet requirements in terms accuracy and robustness. Spectral imaging systems can perform spectroscopy on highly heterogenous samples which opens up a new space of applications. Different architectures are used for these systems, and sometimes they are grouped into multispectral and hyperspectral technologies, which, however, only represents a small part of the relevant system characteristics. More important is the actual selection of wavelengths, the signal to noise ratio over the entire wavelengths range, and the robustness and calibration of the hardware system involved. Only when enough attention is paid to these factors then we can hope to obtain the reproducibility of measurements and the transferability of models that is needed for robust and commercially viable high performance systems.

A strobed LED spectral imaging system is the basis of the patented technology [1] applied here. Figure 1 shows a schematic of the system that can combine multiple diffuse frontlight strobes with backlight strobes and fluorescence emission filters. The camera is a monochrome silicon sensor looking through an integrating sphere, and the sample is placed in an opening port on the opposite side of the sphere. The highly reflective and diffuse coating on the inner side of the sphere will make the light from physically separate high energy LEDs bounce back and forth many times before hitting the sample surface. Up to 20 different wavelengths from $365 \mathrm{~nm}$ to $1050 \mathrm{~nm}$ are used and for all wavelengths the light will be highly diffuse and spatially homogenous. This means that the irradiance orientation distribution is both spectrally and spatially uniform. The different wavelengths are then sequentially strobed and these strobes are synchronized with a 6-12 Mpix camera running at 15-30 frames per second. Thus, a spectral cube of 20 spectral bands and 6 Mpix resolution per band is acquired in less than a second.

*jmca@dtu.dk; phone +45 45253412; www.compute.dtu.dk

Image Sensing Technologies: Materials, Devices, Systems, and Applications V, edited by

Nibir K. Dhar, Achyut K. Dutta, Proc. of SPIE Vol. 10656, 1065604 · @ 2018 SPIE

CCC code: $0277-786 \mathrm{X} / 18 / \$ 18 \cdot$ doi: $10.1117 / 12.2304698$ 


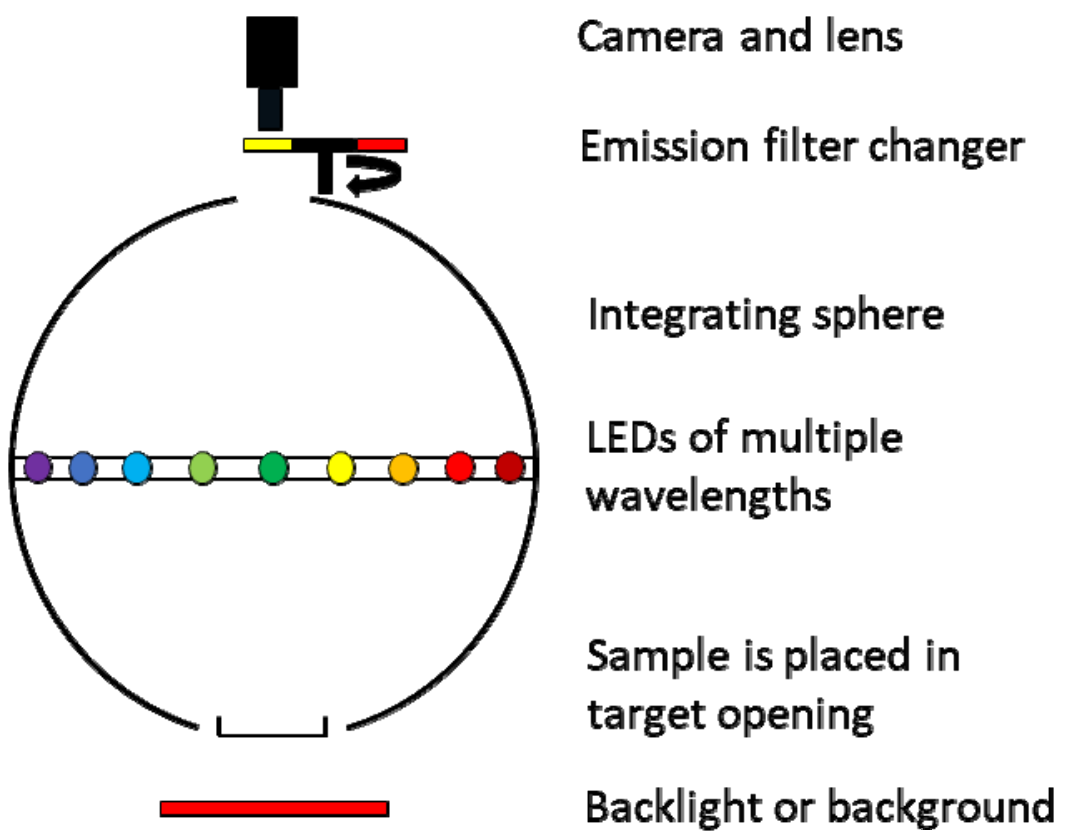

Figure 1 Schematic of the strobed LED imaging system. The system can combine multiple diffuse frontlight strobes with backlight strobes and fluorescence emission filters (VideometerLab principle, image courtesy of Videometer $\mathrm{A} / \mathrm{S}[2])$.

Through a reflectance calibration the pixel values are transformed to reflectance values. The reflectance spectrum in every pixel can then further be extended with fluorescence bands by applying one or more bandpass or longpass filters in front of the camera. This provides further chemical information about each pixel and this information can be analyzed separately or together with the reflectance spectra in an extended spectral cube.

\section{METHODOLOGY}

The discrimination between different types of products in a spectral cube is done by nCDA which is a modified canonical discriminant analysis (CDA). CDA dates around 80 years back and is also known as Fisher discriminant analysis. It is a linear transformation and provides an optimal foreground/background discrimination in the sense that the Rayleigh quotient

$$
R(\mathbf{a})=\frac{\mathbf{a}^{\mathbf{T}} \boldsymbol{\Sigma}_{S} \mathbf{a}}{\mathbf{a}^{\mathbf{T}} \boldsymbol{\Sigma}_{N} \mathbf{a}}
$$

is maximized with respect to the vector a. The multivariate signal dispersion $\boldsymbol{\Sigma}_{S}$ represents the 'between class' variation and the noise dispersion $\boldsymbol{\Sigma}_{N}$ represents the 'within class' variation. Having painted or otherwise selected representative pixels for foreground relating to a given product and also the background noise, then we can estimate $\boldsymbol{\Sigma}_{S}$ and $\boldsymbol{\Sigma}_{N}$. The optimal signal-to-noise ratio $R_{\max }$ in a linearly projected space is obtained at the maximizer $\mathbf{a}^{*}=\underset{\mathbf{a}}{\arg } \max (\mathbf{a})$ of the Rayleigh quotient. Optimizing $\mathbf{a}$ in equation (1) is a generalized eigenvalue problem, and $\mathbf{a}$ is found to be the eigenvector corresponding to the largest eigenvalue. Frequently we will only have two classes: good product and bad product, and in 
this two-class problem there is only one CDA component since the rank of $\boldsymbol{\Sigma}_{S}$ is one. A score image can then be calculated by projecting the spectral image onto $\mathbf{a}^{*}$. The $\mathrm{nCDA}$ is closely related to the CDA. It is extended from CDA with the following extensions:

- Rayleigh-optimized feature set selection among original bands, logarithm of original bands, and all possible bandnormalizations.

- Basis expansion with squared and cubed terms.

- Variable subset selection/shrinkage

- Projection is centered around overall mean.

- Class-weighted noise dispersion $\boldsymbol{\Sigma}_{N}$.

- $\mathbf{a}^{*}$ is scaled such that the maximum absolute class mean projection is 1 .

- $\mathbf{a}^{*}$ is oriented to make class mean projection for the affected skin class positive.

- Score image is shown with fixed scaling from -2 to 2 with e.g. blue-green-red colormap.

In the first step we compare the Rayleigh quotient of the different feature sets, and selects the one with the highest Rayleigh quotient. Figure 2 shows an image of durum wheat (left) and common wheat (right). Common wheat is often used as an adulterant in durum wheat and we want to detect this as an adulteration. We paint representative areas of durum wheat and common wheat and then we calculate the nCDA score images shown in Figure 3. It shows a very good signal to noise ratio in separating durum wheat from common wheat. Figure 4 (left) shows a petri dish with 100 kernels of mixed seeds. These seeds are segmented to individual kernels that are extracted and aligned, and then a mean value for the nCDA score image is calculated for each kernel. Finally, the kernels are sorted row-wise according to this mean. From very common wheat like kernels in the upper left corner to very durum like kernels in the lower right corner. A threshold will reveal 3 common wheat kernels in the sample. 

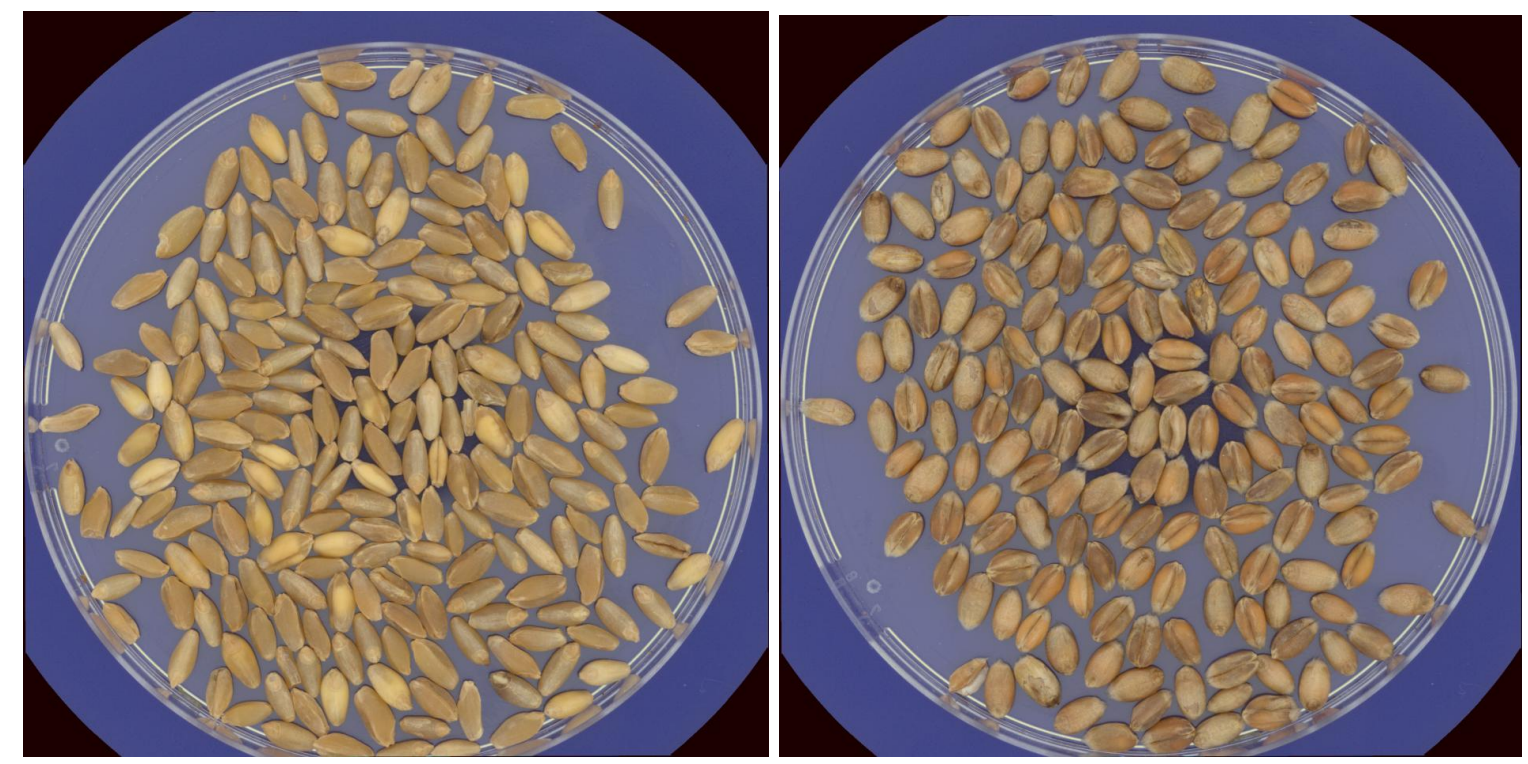

Figure 2 Durum wheat to the left and common wheat to the right.
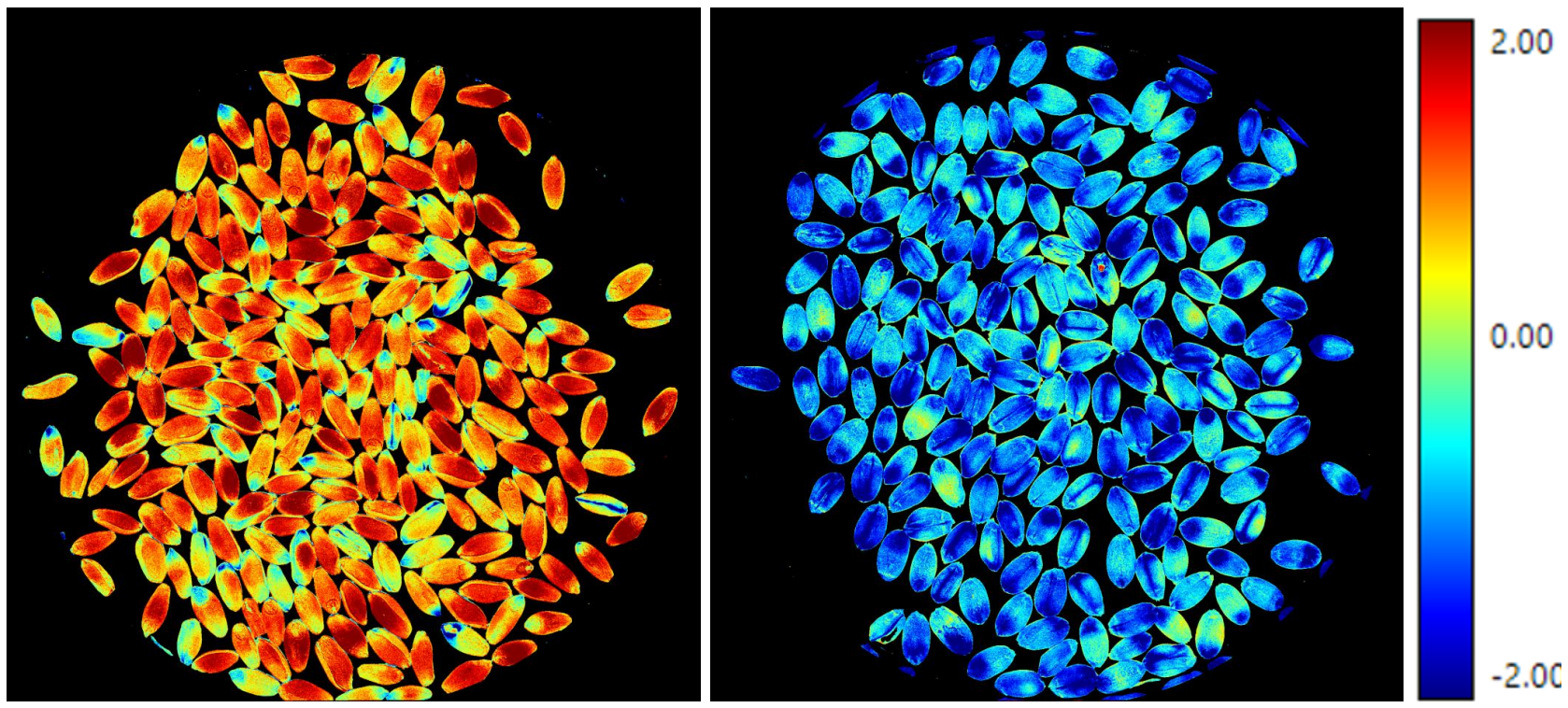

Figure $3 \mathrm{nCDA}$ score image of durum (left) and common wheat (right). On the far right we show the scale and color code of the score image. 

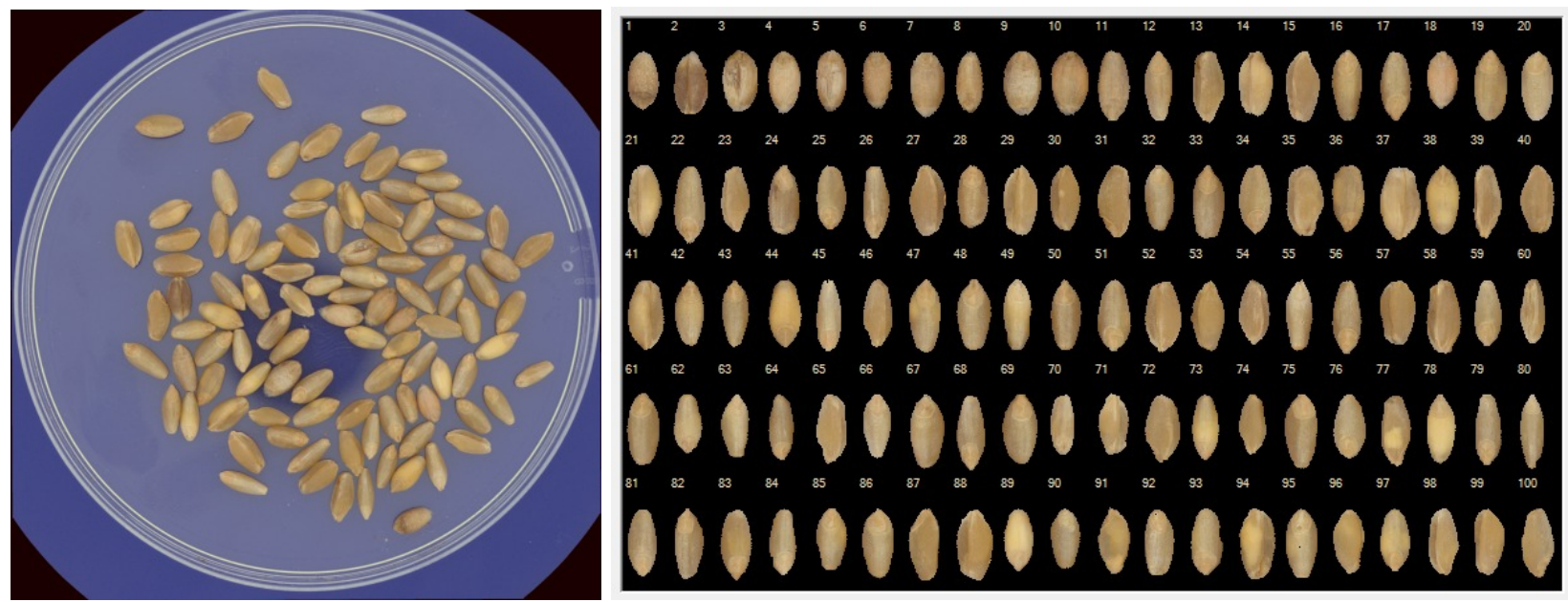

Figure 4100 seeds of a mixed sample automatically segmented and sorted according to likelihood of being durum according to the nCDA.

Table 1 shows results for 2 pure samples and 21 blind samples provided by Lab of Government Chemist (LGC), UK. Real (manually prepared) counts were provided after the analysis (EST \#) was complete. The average error in the counts is less than 1 out of 100 seeds. By including shape parameters this error could most likely be reduced further. All together this has the potential to become a fast and easy way to check authenticity of durum wheat [3]. 
Table 1. Results for 2 pure samples and 21 blind samples provided by LGC, UK. Real (manually prepared) counts were provided after the analysis (EST \#) was complete.

\begin{tabular}{|c|c|c|c|c|c|c|}
\hline $\begin{array}{l}\text { Sample } \\
\text { number }\end{array}$ & Sample name & $\begin{array}{c}\text { REAL \# } \\
\text { of Durum } \\
\text { wheat } \\
\text { seeds }\end{array}$ & $\begin{array}{l}\text { EST \# of } \\
\text { Durum } \\
\text { wheat } \\
\text { seeds }\end{array}$ & $\begin{array}{c}\text { REAL \# } \\
\text { of } \\
\text { Aestivum } \\
\text { wheat } \\
\text { seeds }\end{array}$ & $\begin{array}{c}\text { EST \# of } \\
\text { Aestivum } \\
\text { wheat } \\
\text { seeds }\end{array}$ & $\begin{array}{c}\text { Total } \\
\text { number } \\
\text { of seeds }\end{array}$ \\
\hline 1 & $100 \%$ Durum control & 300 & 300 & 0 & 0 & 300 \\
\hline 2 & $100 \%$ Aestivum control & 0 & 0 & 300 & 300 & 300 \\
\hline 3 & $10 \%$ adulterated & 90 & 89 & 10 & 11 & 100 \\
\hline 4 & $3 \%$ adulterated & 97 & 95 & 3 & 5 & 100 \\
\hline 5 & $100 \%$ adulterated & 0 & 0 & 100 & 100 & 100 \\
\hline 6 & $3 \%$ adulterated & 97 & 95 & 3 & 5 & 100 \\
\hline 7 & $2 \%$ adulterated & 98 & 98 & 2 & 3 & 100 \\
\hline 8 & $5 \%$ adulterated & 95 & 94 & 5 & 6 & 100 \\
\hline 9 & $10 \%$ adulterated & 90 & 90 & 10 & 11 & 100 \\
\hline 10 & $0.5 \%$ adulterated & 199 & 195 & 1 & 4 & 200 \\
\hline 11 & $0 \%$ adulterated & 100 & 98 & 0 & 2 & 100 \\
\hline 12 & $0.5 \%$ adulterated & 199 & 198 & 1 & 2 & 200 \\
\hline 13 & $5 \%$ adulterated & 95 & 95 & 5 & 5 & 100 \\
\hline 14 & $5 \%$ adulterated & 95 & 95 & 5 & 5 & 100 \\
\hline 15 & $2 \%$ adulterated & 88 & 87 & 2 & 3 & 90 \\
\hline 16 & $10 \%$ adulterated & 90 & 91 & 10 & 9 & 100 \\
\hline 17 & $0 \%$ adulterated & 100 & 99 & 0 & 1 & 100 \\
\hline 18 & $100 \%$ adulterated & 0 & 0 & 100 & 100 & 100 \\
\hline 19 & $0.5 \%$ adulterated & 199 & 197 & 1 & 0 & 200 \\
\hline 20 & $2 \%$ adulterated & 98 & 98 & 2 & 2 & 100 \\
\hline 21 & $100 \%$ adulterated & 0 & 0 & 100 & 100 & 100 \\
\hline 22 & $0 \%$ adulterated & 100 & 100 & 0 & 0 & 100 \\
\hline 23 & $3 \%$ adulterated & 97 & 96 & 3 & 4 & 100 \\
\hline
\end{tabular}

\section{ADDITIONAL RESULTS AND DISCUSSION}

\subsection{Coating of food and pharma products}

Figure 5 shows two samples of the same minitabs. The only difference between the two images is that the tabs on the left are uncoated. In standard color representation (sRGB D65) there is no visible difference between the two populations and a check of proper coating does not seem feasible.

If we train on uncoated and coated pixels and use the nCDA to discriminate between these two populations then the resulting score images are shown in Figure 6 (left and center). The graph in Figure 6 (right) shows the histogram of the nCDA in the two score images. We see that coated minitabs have a mean of +1 and uncoated minitabs have a mean of -1 . The histogram is based on pixels and not individual minitabs. In case the mean was taken over each minitab then the discrimination will be even better.

Similar results can be obtained for other coatings and other products. Examples are coating of seeds with pesticides, coating of pellets, and glazing of shrimps. 

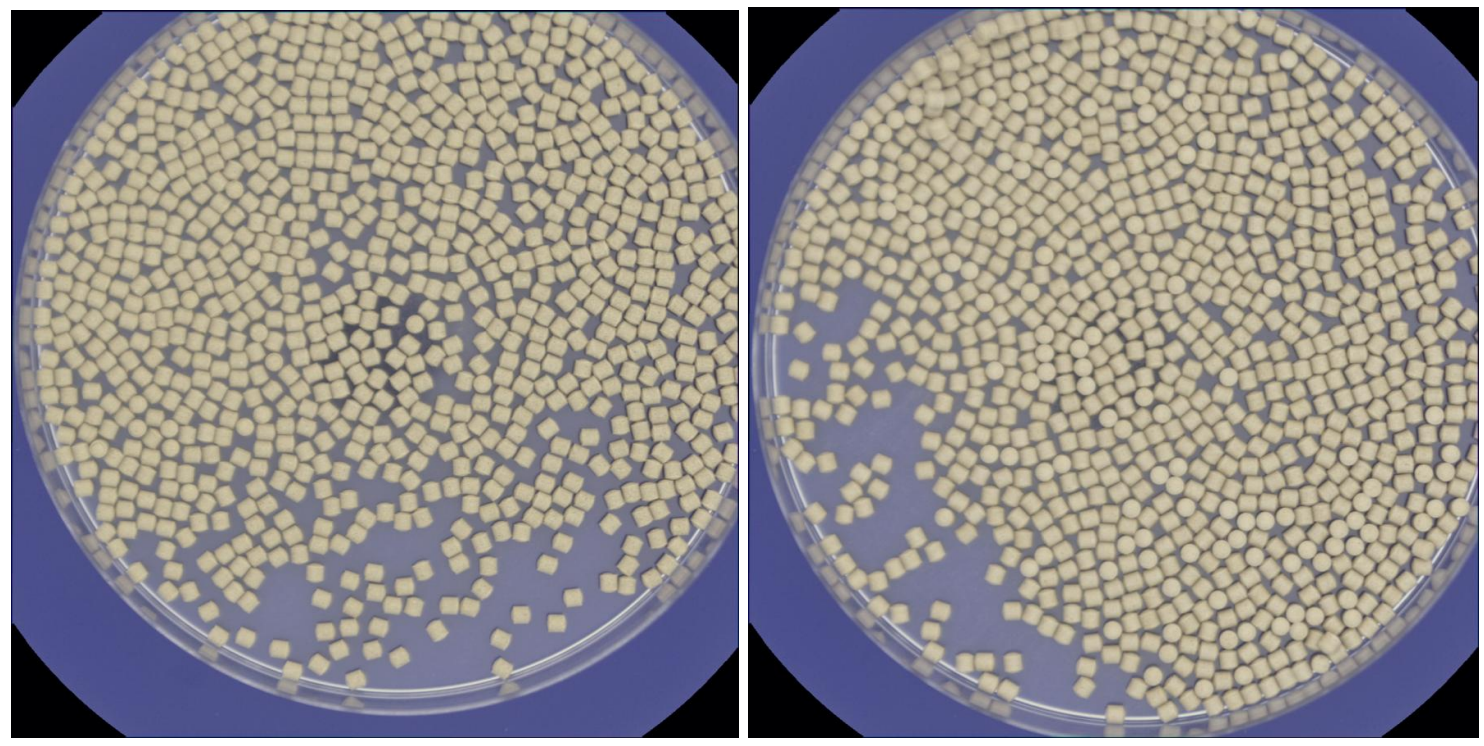

Figure 5 Minitabs which are uncoated (left) and coated (right). No real contrast is seen in these sRGB D65 representations.
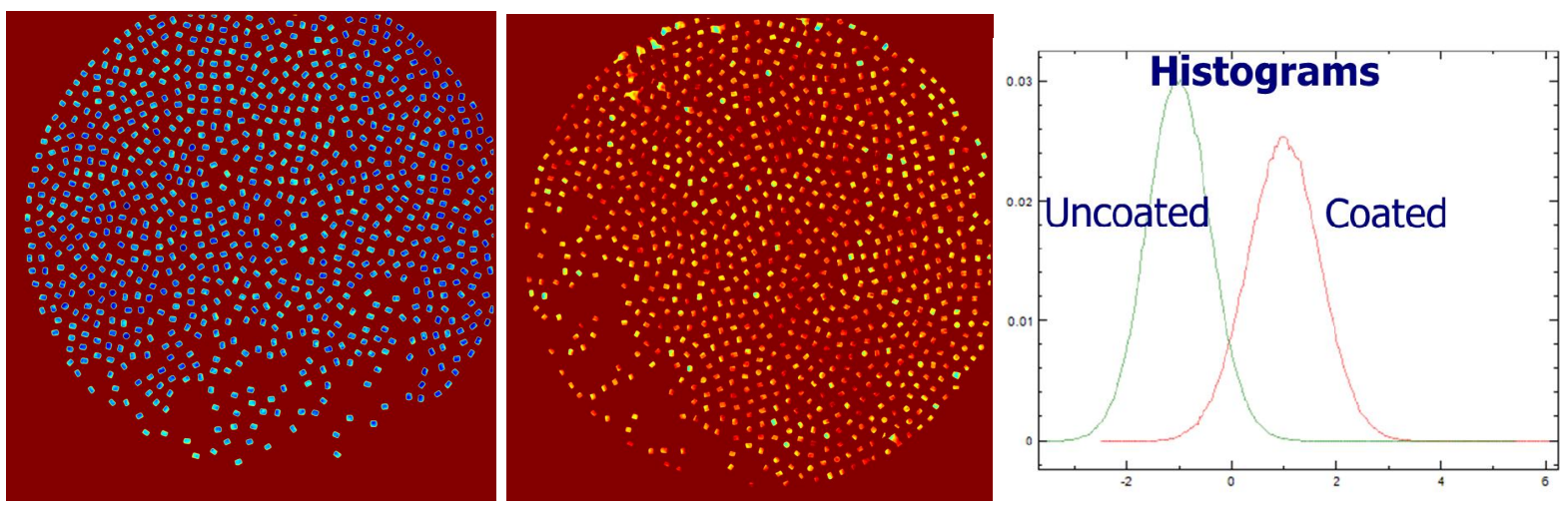

Figure $6 \mathrm{nCDA}$ of uncoated minitabs (left), coated minitabs (center), and histogram of nCDA on the two populations.

\subsection{Food contamination}

Figure 7 (left) shows a powder that we want to analyze without imposing any knowledge of composition. The minimum noise fraction (MNF) transformation [4] is used to get orthogonal components. Figure 7 (right) shows the first MNF called MNF1. MNF1 contains the powder structure. Figure 8 shows MNF2 (left) and MNF3 (right). MNF2 appears to contain the most prominent admixture in the powder and this component allows to assess the amount of admixture as well as the blending homogeneity. MNF3 appears to contain other contaminants without any impact from MNF1 and MNF2 due to MNF being an orthogonal transformation. 


\subsection{Counterfeit detection}

Besides the adulteration issues discussed previously on durum wheat and common wheat we see other types of fraud and mislabeling e.g.

- Long grained rice in basmati rice [5]

- Plastic rice in rice [5]

- Olive leaves in oregano [5]

- Ground peanut in ground almond [5]

- Horse meat in minced beef [7]

- $\quad$ Pork meat in minced beef [8]

- Frozen-then-thawed meat in fresh meat [6]

These and other examples have been handled by the technology presented here.

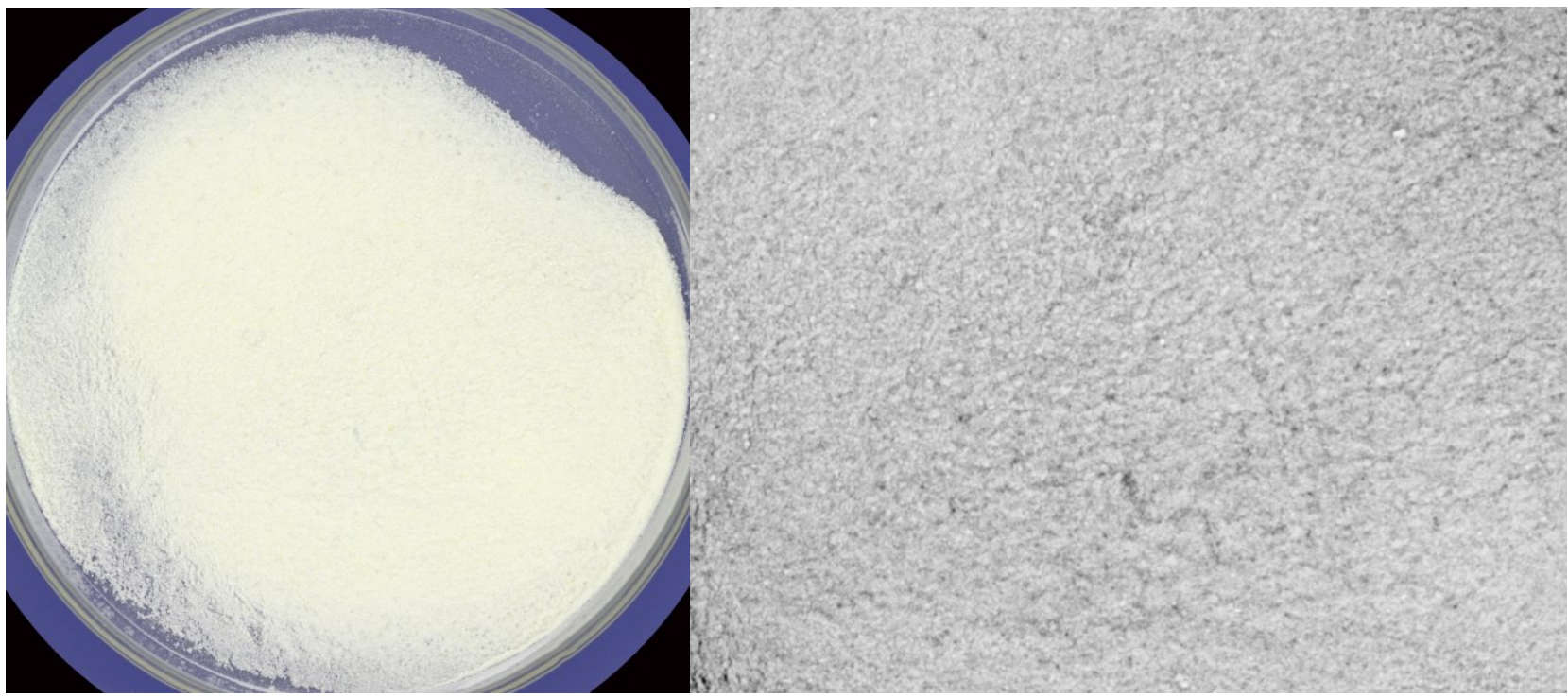

Figure 7 Powder (left) and first MNF (right). The first MNF (MNF1) shows the powder structure.
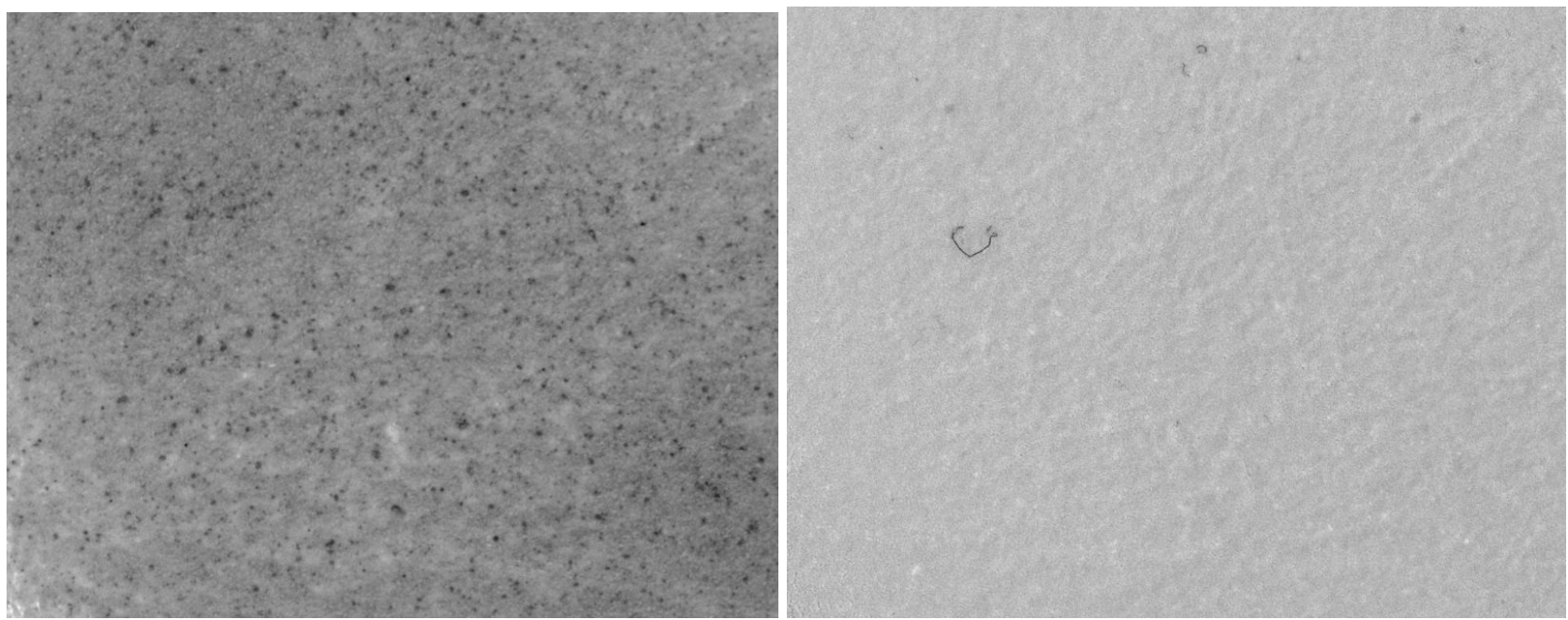

Figure 8 Second MNF (left) showing an admixture powder, and third MNF (right) showing impurities. 


\section{CONCLUSION}

Strobed LED spectral imaging systems in combination with a good calibration procedure and machine learning represents a fast, non-destructive, and versatile solution to a broad range of analysis challenges in the agricultural and food industry. This technology has the potential to augment existing technologies and provide more valuable information related to the integrity of food and feed consumed today.

\section{REFERENCES}

[1] Carstensen, J.M.and Folm-Hansen, J., "Apparatus and a method of recording an image of an object”, US patent US7119930B1 (2006).

[2] https://www.videometer.com (21 March 2018).

[3] Malcolm Burns, "EVID4 Evidence Project Final Report (Rev. 06/11)" http://randd.defra.gov.uk/Document.aspx?Document=13082_FA0136EVID4_final_report.pdf (March 21 2018)

[4] Green, A.A., Berman, M., Switzer, P., Craig, M.D., "A transformation for ordering multispectral data in terms of image quality with implications for noise removal", IEEE Transactions on Geoscience and Remote Sensing ( Volume: 26, Issue: 1, Jan 1988 ), 65-74, (1988).

[5] Nixon, G., Burns, M., "Final report: Application of multispectral imaging (MSI) to food and feed sampling and analysis", https://www.food.gov.uk/sites/default/files/fs301017finrep.pdf (21 March 2018)

[6] Rodopi, A., Panagou, E.Z., Nychas, G.J.E., "Rapid detection of frozen-then-thawed minced beef using multispectral imaging and Fourier transform infrared spectroscopy", Meat Science, Volume 135, 142-147, (2018).

[7] Rodopi, A., Panagou, E.Z., Nychas, G.J.E., "Multispectral imaging (MSI): A promising method for the detection of minced beef adulteration with horsemeat", Food Control, Volume 73, Part A, 57-63, (2017).

[8] Rodopi, A., Pavlidis, D.E., Mohareb, F., Panagou, E.Z., Nychas, G.J.E., "Multispectral image analysis approach to detect adulteration of beef and pork in raw meats", Food Research International, Volume 67, 12-18, (2015). 